\section{Chronische Niereninsuffizienz}

Helga Peter ${ }^{1}$ und Thomas Penzel ${ }^{2}$

${ }^{1}$ Marburg, Deutschland

${ }^{2}$ Interdisziplinäres Schlafmedizinisches Zentrum, Charité Universitätsmedizin Berlin, Berlin, Deutschland

\section{Synonyme}

Chronisches Nierenversagen

\section{Englischer Begriff}

chronic kidney failure

\section{Definition}

Sich über Monate oder Jahre entwickelnde Niereninsuffizienz mit progredienter Verminderung der Anzahl funktionsfähiger Nephrone und damit der glomerulären Filtrationsrate.

Siehe auch

- „Bluthochdruck“

- „Nierenerkrankungen“ 